\section{Complementary}

Medicine Research

Practice $\mid$ Methods|Perspectives

\section{Editorial}

Complement Med Res 2017;24:276-277

DOI: $10.1159 / 000482020$
Published online: October 18, 2017

\title{
The Utilization Paradox
}

\section{Frauke Musial}

National Research Center in Complementary and Alternative Medicine (NAFKAM), Department of Community Medicine, UiT The Arctic University of Norway, Tromsø, Norway

Patients and non-patients use Complementary and Alternative Medicine (CAM), either to treat or to prevent disease and symptoms. The numbers differ, depending on the definition of CAM and the country, but the use in the Western world is generally substantial. Thus, it is not surprising that $71 \%$ of the Swedish respondents of the survey conducted by Wemrell et al. [1] answered that they had used at least 1 form of CAM in the past year. Sweden is well within the CAM utilization range of other Western countries. Moreover, CAM utilization tends to be substantially higher in Asian countries such as China or India. In many of these countries, some interventions from the CAM spectrum, e.g. acupuncture, are considered the predominant form of medicine and are by far not seen as complementary or alternative.

In some European countries, such as in Norway and similarly in Sweden, CAM is per definition practiced outside the public healthcare system. In Norway, the definition goes as far is this: if a CAM procedure is practiced within the public healthcare system and by healthcare personnel, it is still defined as treatment outside the official healthcare system. This situation might impose a significant threat to patient safety and rights. In other European countries, such as in Germany and the UK, the situation is a slightly better one because selected CAM procedures are practiced within the healthcare system, or they are reimbursed by the health insurance companies, such as in Germany, which improves patient rights. However, treatment can still take place outside the official healthcare system.

A closer look at Europe (CAMbrella, the Seventh EU Framework Programme (FP7), Topic: FP7-HEALTH-2009-3.1-3: Complementary and Alternative Medicine, Coordination and support action, Grant Agreement No. 241951) reveals that whether CAM is part of the healthcare system or not depends to a large extend on the national regulations and guidelines (https://uit.no/om/enhet/artikkel?p_document_id = 380656ep_dimension_id = 88112) [2]. The only exception is the use of medical CAM products, which are subject to the same market authorization procedures as other medical products, with the possibility to go without the documentation of efficacy. For practitioner-dependent CAM interventions, there is an extraordinary diversity with regard to the regulation of CAM practice [2]. Given the situation that CAM procedures are in widespread use, the current situation might be considered a threat to patient safety.

Whether a CAM intervention is available as part of the official healthcare system is less dependent on scientific evidence than one should assume in times of evidence-based medicine and guidelines. Experience shows that CAM procedures can make their way into mainstream healthcare if they are economically attractive, e.g. for health insurance companies. A good example for this trend are the German Acupuncture Trials, which were financed by some of the German health insurance companies and have made acupuncture available for selected indications (back pain and knee osteoarthritis); however, this concerns a reasonably large number of patients within the German healthcare system.

\section{KARGER}

(c) 2017 S. Karger GmbH, Freiburg

Fax +497614520714
Frauke Musial, $\mathrm{PhD}$

National Research Center in Complementary and Alternative Medicine (NAFKAM), Department of Community Medicine

UiT The Arctic University of Norway

9037 Tromsø, Norway

frauke.musial@uit.n。 
To date, most CAM interventions are still under research and funding resources are limited, in particular for researchers who aspire to be independent and free from potential conflicts of interest. European citizens are underprivileged compared to populations of other regions of the world, and Europe has some way to go if the same financial engagement with regard to CAM research as in Australia, Asia, and North America is to be pursued. Europe limbs behind the emerging global trend supporting a broad research repertoire, including qualitative and comparative effectiveness research [3].

At the same time, at least selected CAM interventions are well accepted, not only by patients, as the surveys on CAM use consistently show, but also among medical doctors who practice CAM interventions and medical students who engage in courses on alternative therapies - if they are available [4]. In part, this even holds for interventions where the scientific evidence is scarce or simply absent. What is it, then, that drives patients and conventional-healthcare personnel, who - due to their education - are supposed to practice within the framework of scientific evidence, to use interventions even though their specific effects have not been confirmed?
Patients seek relief from their symptoms, and, since in most European countries they have to pay CAM treatments and products out of their own pocket, they must find it worthwhile to go for this investment. I would personally always assume that healthcare professionals have, as a general attitude, a healing intent when they meet patients. And healthcare professionals may experience the same - that patients find relief and support when using CAM interventions. As a scientist within healthcare research, I would wish for this relief to be based upon scientific evidence. At the same time, I have to admit that for many chronic diseases powerful, evidence-based conventional interventions are rare and often have considerable side effects. Therefore, I would assume, it is that patients are looking for alternatives, even if these lack safety and scientific evidence.

I find it to some extend comforting that patients find professionals who are willing to cross the borders of their professions, with the intend to relief suffering. However, I wish that enough funding resources were made available to - apart from the question of research-based evidence for effect - at least secure patient safety for the sake of both the patient and the professional.

\section{References}

1 Wemrell M, Merlo J, Mulinari S, Hornborg AC: Twothirds of survey respondents in southern Sweden used complementary or alternative medicine in 2015. Complement Med Res 2017;24:DOI: 10.1159/000464442.

2 Wiesener S, Falkenberg T, Hegyi G, Hök J, Roberti di Sarsina P, Fønnebø V: Legal status and regulation of complementary and alternative medicine in Europe. Forsch Komplementmed 2012;19(suppl 2):29-36.
3 Hök J, Lewith G, Weidenhammer W, Santos-Rey K, Fønnebø V, Wiesener S, Falkenberg T: International development of traditional medicine / complementary and alternative medicine research - what can Europe learn? Forsch Komplementmed 2012;19(suppl 2):4450.
4 Jocham A, Berberat PO, Schneider A, Linde K: Why do students engage in elective courses on acupuncture and homeopathy at medical school? A survey. Complement Med Res 2017;24:DOI: 10.1159/000468539. 